\title{
The inflection of Tigre weak-final and strong verbs
}

\author{
Noam Faust \\ Université Paris 8, CNRS SFL \\ noam.faust@univ-paris8.fr
}

\begin{abstract}
This paper provides a complete, exclusively phonological account of the alternations in the paradigms of the two largest verbal types in the Ethio-Semitic language Tigre. It is proposed that "weakfinal" verbs are constructed using the same templates and vocalizations as "strong" verbs. All of the differences between the two inflectional paradigms follow from weak-final verbs involving a vowel /e/ where strong verbs position a consonant. The analysis, conducted with the tools of Strict CV Phonology and Element Theory, is the first of its kind for Tigre.
\end{abstract}

Keywords: morphology; non-concatenative; phonology; Semitic; Tigre; weak verbs

\section{Introduction}

This paper examines the alternations in the paradigms of the two largest verbal types in Tigre, an Ethio-Semitic language: "strong" verbs and "weakfinal" verbs. Examples are provided in (1). The two verbs appear in the same verbal "template" or class called "Type A", which is the basic class of verbs in the language. Since they share a template, they are expected to appear with the same vowels and syllable structure. The verb in (1a) is "strong" because the three elements of the root (henceforth "radicals") appear in all inflected forms (1a). A verb is called "weak" when one of the radicals is absent or inconsistently realized in some of the inflected forms. The verb in (1b) is therefore weak-final: it seems to lack a third and final radical in all of the forms except for the 3FPL.IMPV, where one finds a consonant [j] (in bold). As is very common in Semitic, the absence of the radical is accompanied by changes in the vocalization of the stem. In the $1 \mathrm{SG} . P F V$ and the SBJV stems one finds [e:] and [e] respectively in the weak-final form where the parallel strong verb exhibits [əb], and in the 3MPL.IMPV the suffix of the weak final verb is $[-\mathrm{u}]$, whereas in the strong verb it is $[-\mathrm{O}]$. 
(1) Tigre strong vs. weak-final verbs representative examples

\begin{tabular}{|c|c|c|c|c|c|c|c|}
\hline & & \multicolumn{2}{|c|}{ perfect } & \multicolumn{2}{|c|}{ imperfect } & \multirow{2}{*}{\multicolumn{2}{|c|}{ subjunctive }} \\
\hline & $\sqrt{ }$ & $3 \mathrm{MSG}$ & $1 \mathrm{SG}$ & $3 \mathrm{MPL}$ & $3 \mathrm{FPL}$ & & \\
\hline a. & $\sqrt{\mathrm{rkb}}$ & rakba & rəkəb-ko & ti-rəkb-o & ti-rakb-a & -rkəb & 'find' \\
\hline b. & $\sqrt{\mathrm{st}} ?$ & sata & səte:-ko & ti-sətt-u & ti-satj-a & -ste & 'drink' \\
\hline
\end{tabular}

There are many other alternations that emerge within each verbal type and between them. The goal of this paper is to account for all of these alternations. While the full paradigms have appeared in descriptive work (Raz 1980; 1983; Elias 2014), no account of the alternations exists. Indeed, detailed accounts of entire Semitic paradigms are rare in general; besides my own work (Faust 2017a; Faust \& Lampitelli 2020), I am only aware of Chekayri \& Scheer (2003), which treats Classical Arabic, a language with no native speakers. To be sure, the forms in this paper have all been elicited by the author from a speaker of the Samhar dialect of Tigre. ${ }^{1}$

In (1b) above, I have left the identity of the third radical of 'drink' unspecified. Traditional analyses of such paradigms associate this radical with the phoneme /i/ (e.g., Raz 1980), relying on the realization [j] of the 3FPL.IMPV. In this paper, I will argue that that radical is $/ \mathrm{e} / .^{2} \mathrm{I}$ will show how, with the help of the Theory of Elements (Kaye et al. 1985; Backley 2011) and a single phonological rule, this hypothesis is capable of accounting insightfully for all of the deviations of weak-final forms from the regular pattern, throughout the inflectional paradigms of all three bases. Importantly, I will make no specific morpho-phonological statement regarding weak final verbs: the account is completely phonological.

The following section introduces some relevant aspects of the phonology of the Samhar dialect of Tigre and the theoretical framework adopted. Section 3 presents the analysis, and section 4 concludes the paper.

\section{Background: Tigre phonology and the theoretical framework}

\subsection{Phonological facts}

Tigre is usually described as having six vocalic phonemes /i,u,e,o,ə,a/ (Leslau 1945). There is a distinct epenthetic vowel [i]; the vowel /ə/, while

${ }^{1}$ This dialect is slightly different from the Mansai dialect, which features in most of the literature on Tigre. I assume here that the speaker is representative of his dialect.

${ }^{2}$ A similar proposal is made for the parallel verbal type in Wolane, a related EthioSemitic language, in Meyer (2006). 
it does alternate with zero, is not epenthetic. An important aspect of Tigre phonology is the harmony discussed in Palmer (1956). The vowel /ə/ is obligatorily realized as [a] if it immediately precedes an [a] (2). ${ }^{3}$

(2) Tigre /o/ realized as [a] before [a] (Palmer 1956)

$\begin{array}{llllll}\text { fərəs } & \text { 'horse' } & \text { farasa } & \text { 'her horse' } & \text { fərəski 'your(FSG) horse' } \\ \text { mided } & \text { 'grindstone' } & \text { midadna } & \text { 'our grindstone' } & \text { midədu } & \text { 'his grindstone' }\end{array}$

If so, there are two distinct phonemes in Tigre $-/ \mathrm{\partial} /$ and $/ \mathrm{a} /-$ and the quality of $/ \mathrm{\partial} /$ assimilates to that of [a] when they appear in this order.

Two additional facts about the interplay between /o/ and /a/ suggest that the difference is not only in quality, but also in quantity. The first is that phonetically, one may find two lengths for [a] word-medially. Phonetically short [a] is always the result of assimilation, and can usually be shown to alternate with [ə]. Phonetically long [a:] never alternates with $[ə]$. It may be concluded that the former is $/ \mathrm{\partial} /$, and realized as short [a] through assimilation. Phonetically long [a:] is /a/ and underlyingly long.

Secondly, [ə] never appears at the absolute right edge of the word; all final low vowels have the quality [a], are short, and trigger harmony (as in 2 above). There are two ways of understanding this distributional fact. Either /a: / is disallowed finally, and $[\mathrm{a}]$ is the realization of $/ \mathrm{\partial} /$ at the right edge; or $/ \partial /$ is disallowed word-finally, and /a: / is shortened at the right edge. The second hypothesis is preferable for three reasons. First, there is no reason for $/ \mathrm{a} /$ to lower at the right edge. Second, all other vowels are phonetically long in open syllables, and all are allowed word-finally, where they are phonetically short. Third, all of these final, phonetically short vowels become long when another suffix is added: [tirakba] 'find.2/3FPL.IMPF', [tirakba:-ka] 'find.2/3FPL.IMPF-OBJ.2MSG'. I conclude that (i) all vowels except $/ \partial /$ are phonologically long; ${ }^{4}$ (ii) there is a morpheme structure constraint banning phonologically-short /ə/ word-finally; and (iii) final, phonologically-long vowels are realized short. None of these conclusions are

${ }^{3}$ Pharyngeals and ejectives also lower preceding vowels. For a full account of the harmony facts (with the additional rounding harmony of Samhar Tigre), see Faust (2017b).

4 This claim is consistent with previous work on Tigre (Lowenstamm \& Prunet 1988; Faust 2014), as well as on other Ethiosemitic languages (for Tigre, see Leslau 1945). Lowenstamm and Prunet (1988) note that in the Mansaf dialect, all vowels except [ə] alternate with $[\mathrm{i}]$ in a non-final closed syllable. Assuming long vowels cannot survive in closed syllables, this situation is expected. However, in the Samhar dialect discussed here, there is no quality reduction in closed syllables, e.g., [ge:sa] 'he went', [ge:sko] 'I went', *[gisko]. 
cross-linguistically surprising: neutralization of vowel length at the right edge is typologically common (cf. the similar fact of Arabic discussed in McCarthy 2005; Faust \& Ulfsbjorninn 2018).

A third and final general remark concerns glides. On the surface, these sounds never surface as geminate, unlike all other consonants (except gutturals). Verbs of Type B (otherwise not treated in this paper) illustrate this fact. These verbs are characterized by a medial geminate and a vocalization $\langle\mathrm{a}, \mathrm{a}\rangle$ in the perfective, e.g., [habbara] 'he connected'. The verb [ $\mathrm{k}^{2}$ ajara] 'he replaced' is clearly of Type $\mathrm{B}$, but the $/ \mathrm{j} /$ is not realized as geminated. I conclude with Raz $(1980 ; 1983)$ that underlying geminate glides surface as simplex.

\subsection{The frameworks adopted}

In their analysis of the assimilation data, Lowenstamm and Prunet (1988) provide an account of the vocalic system in the framework of Element Theory (as construed by Kaye et al. 1985). This paper will adopt that account. To illustrate, consider its application to the assimilation of $/ \mathrm{\partial} /$ into [a].

The three rightmost vocalic expressions in (3) are simplex: they are comprised of a single element which heads the expression ("v" represents the absence of lexical information; head status is represented by an underline), and are realized as $[\mathrm{u}, \mathrm{i}, \mathrm{a}]$ respectively. To their left, the two mid vowels $[\mathrm{o}, \mathrm{e}]$ are represented as combinations of head $\underline{\mathrm{U}}$ and $\mathrm{I}$ respectively and a non-head A. The vowel $[\theta]$ is represented as an unheaded expression which nevertheless contains A; and the empty set, comprising only of "v"s, is the epenthetic vowel. ${ }^{5}$

(3) The Tigre vowel inventory according to Lowenstamm \& Prunet (1988)

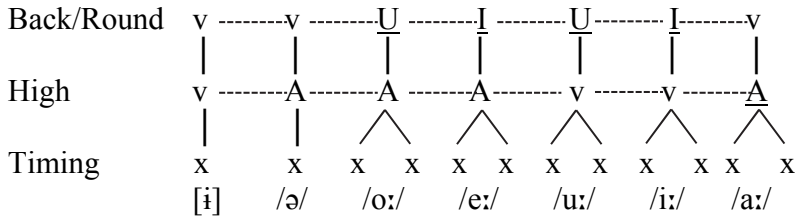

${ }^{5}$ Lowenstamm and Prunet (1988) account for the length distinctions and for the specific repertoire of Tigre by the following two well-formedness constraints: i. Headed elements must branch, and ii. I and U must be heads of their expressions. Assuming that expressions cannot have two heads, this covers all and only the six lexical vowels of Tigre (see also Faust 2014). 
The harmony that the vowel / / / undergoes can be attributed to a preference for headed expressions. Put very simply, whenever the non-headed / $/$ / immediately precedes headed /a/, there is assimilation in headedness and $/ \mathrm{\partial} /$ is realized as short $[\mathrm{a}]:^{6}$

(4) Harmony in Headedness: / ...əta:t/ $\Rightarrow$ [ata:t]

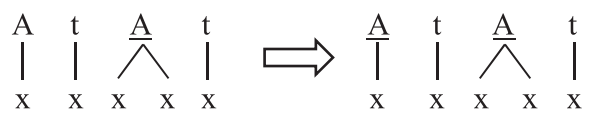

Underlying length is also important for the analysis of glides, which are often assumed to be the consonantal version of vocalic expressions. If phonetically simple glides can be underlyingly geminated, what about underlyingly singleton glides? The realization of these, we will see, depends on their environment.

Element Theory deals with the representation of segments. Templates, in turn, will be represented here following Strict CV theory (Lowenstamm 1996; Scheer 2004), an offspring of the theory of Government Phonology (Kaye et al. 1990). In this approach, the only skeletal unit replicates the unmarked syllable CV. A major advantage of this approach is that it avoids attributing two templates to two related words with different surface syllabifications. Thus, as presented in (5), the templates of the base in [kəlib] 'dog' and [kəlb-u] 'his dog' are identical in their number of CV units (other aspects of the representations will be explained below):

(5) The templates of [kəlib] and [kəlb-u] in Strict CV Phonology
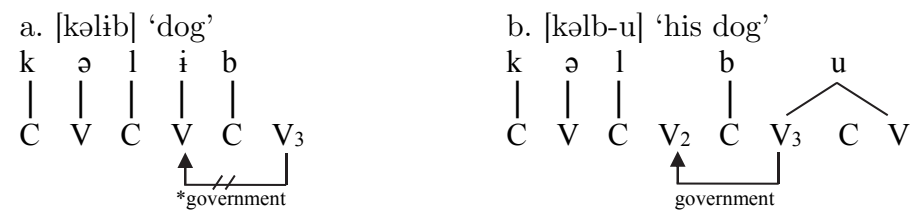

Empty nuclei (i.e., empty V-slots) come in two types: final empty nuclei and medial ones. Final empty nuclei $\left(\mathrm{V}_{3}\right.$ in $\left.5 \mathrm{a}\right)$ are parametrically allowed (or "licensed"), but are unable to govern. Non-final empty nuclei $\left(\mathrm{V}_{2}\right.$ in $5 b)$ may remain unrealized if they are "governed" by a following contentful nucleus ( $\mathrm{V}_{3}$ in $5 \mathrm{~b}$ ). Thus, in (5b), $\mathrm{V}_{2}$ remains silent; but in (5a) the same nucleus is realized as the epenthetic vowel [i].

${ }^{6}$ For more sophisticated, alternative analyses, see Faust (2017b) and Carvalho \& Faust (2017). 
Furthermore, (5b) exemplifies the representation of length in Strict CV Phonology. A long vowel is represented as one element occupying two V-slots. The engulfed C-slot remains unrealized. The representation of geminates, which we will encounter later in the paper, is analogous, with the expression branching onto two C-slots. Finally, (5b) also illustrates the present treatment of final length neutralization: word-final vowels occupy two nuclei, but are realized short.

\section{Analysis}

In the ensuing analysis, each of the three verbal aspects will be discussed in a different section in the following order: imperfective, perfective, subjunctive.

\subsection{The imperfective}

The table in (6) presents the inflectional paradigms of the two types of verb in the imperfective, characterized by the gemination of the second radical. ${ }^{7,8}$

(6) Strong and weak-final imperfective paradigms in Tigre

\begin{tabular}{|l|l|l|l|}
\cline { 2 - 4 } \multicolumn{2}{c|}{} & 'find' & 'drink' \\
\hline SG & 1 & i-rəkkib & i-sətte \\
\hline \multirow{6}{*}{} & $2 \mathrm{M}$ & ti-rəkkib & ti-sətte \\
\cline { 2 - 4 } & $2 \mathrm{~F}$ & ti-rəkb-i & ti-sətt-i \\
\cline { 2 - 4 } & $3 \mathrm{M}$ & li-rəkkib & li-sətte \\
\cline { 2 - 4 } & 3F & ti-rəkkib & ti-sətte \\
\cline { 2 - 4 } & &
\end{tabular}

\begin{tabular}{|l|l|l|l|}
\cline { 2 - 4 } \multicolumn{2}{|c|}{} & 'find' & 'drink' \\
\hline PL & 1 & in-rəkkib & in-sətte \\
\hline \multirow{4}{*}{} & $2 \mathrm{M}$ & ti-rəkb-o & ti-sətt-u \\
\cline { 2 - 4 } & $2 \mathrm{~F}$ & ti-rakb-a & ti-satj-a \\
\cline { 2 - 4 } & $3 \mathrm{M}$ & li-rəkb-o & li-sətt-u \\
\cline { 2 - 4 } & $3 \mathrm{~F}$ & ti-rakb-a & ti-satj-a \\
\cline { 2 - 4 } & &
\end{tabular}

The strong paradigm presents three stems on the surface: unsuffixed [rəkkib] and suffixed [rəkb-] and [rakb-]. The quality of the vowel in [rakb] is the clear harmonic influence of the following [a]: this stem [a] is underlyingly $/ \mathrm{o} /$. The suffixed stem does not have a medial geminate because geminates are not allowed in coda position (more on this below). Since the

7 The data reported in $\operatorname{Raz}(1980 ; 1983)$ and Lowenstamm \& Prunet $(1988)$ are crucially different from what I found in my fieldwork. The suffixes ending with [a] in the present account trigger harmony; they do not in the Mansaf data. The speaker I worked with asserts that harmony applies in both dialects.

${ }^{8}$ Some prefixes in this paradigm are in advanced stages of erosion (Faust 2015; Voigt 2004; 2009). 
vowel [i] is the epenthetic vowel, one can conclude that the imperfective aspect is expressed by a single template, with only one lexical vowel, an unheaded A, and pre-specified gemination:

(7) Basic template of Tigre imperfective

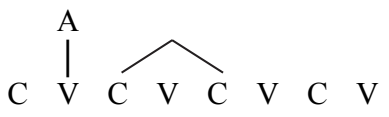

The variation in the surface form of the stem is explained in (8). In the unsuffixed stem (8a) there are three empty nuclei in a row. The final empty nucleus is licensed and remains empty. It may therefore not govern the preceding nucleus, which must be realized. Its realization through [i]-epenthesis is represented by the dashed line. The preceding nucleus is thus governed and silent. In contrast, in the suffixed form in (8b) the final nucleus hosts a lexical vowel (I assume stem-final nuclei are available to suffixal vowels). $V_{3}$ is therefore governed and will not be realized. As a result, it cannot govern the nucleus of the geminate, which accounts for the phonetic simplification of the geminate. ${ }^{9}$

(8) Unsuffixed and suffixed strong imperfectives: [rəkkib] (8a) and [rəkbo] (8b)

a.

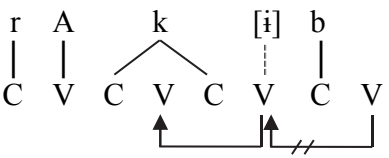

b.

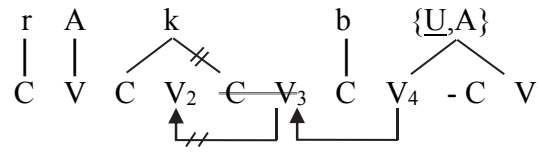

By analogy, the stem of the weak verb must place the weak root in the same template (7). The resulting stems are three in number, not essentially two as in the strong paradigm: unsuffixed [sətte], suffixed [sətt-u] and [satj-a]. Each of the three presents a different problem for the analysis. For the unsuffixed [sətte], one has to explain how the vowel [e] is derived from the absence of a lexical vowel and the third element of the root. The second stem, 2/3MPL [satt-u], nicely illustrates how the gemination is preserved

${ }^{9}$ There are other alternatives here. $\mathrm{V}_{3}$ may be realized despite it being governed in order to maintain the geminate and yield *[rəkkibo]; or the geminate may be separated by an epenthetic vowel to yield *[rekikbo]. I assume that both options fare less well in terms of the requirements of the language, possibly for length reasons. Also, note that in (8b), there remains an empty, unrealized CV unit in the middle of the template. Recognizing this as a weakness, I will assume without further discussion that a general phonological principle prunes such template-medial CV units (see Gussmann \& Kaye 1993 for a similar assumption). Specifically in (8b), once $\mathrm{CV}_{3}$ is pruned, it is $\mathrm{V}_{2}$ that is governed by $\mathrm{V}_{4}$. 
in the weak final verb, although it is not part of the parallel strong form [rəkb-o]; [sətt-u] also presents a problem in the form of the quality of the suffixal vowel, which is [-u] instead of [-o]. Finally, the 2/3MPL [satj-a], which parallels strong [rakba], provides what looks like a direct realization of the third element: a glide [j]. One may hypothesize that the third element of the root is $/ \mathrm{j} /$ or $/ \mathrm{i}$ / (as mentioned, this is indeed the traditional view). But this view does not solve the two other problems, most crucially the first one: it is unlikely that the sequence [sətte] is synchronically the result of $/ \mathrm{s} ə t \mathrm{tj} /$, like [rəkkib] is the result of $/ \mathrm{r} ə \mathrm{kkb} /$.

For this reason, I propose to consider that the third element of the root is /e/. As we saw, /e/ is a headed expression, and will therefore spread onto two positions. Although it is realized short at the right edge, it still maintains its quality, as presented in (9).

(9) Unsuffixed weak verb with the root $\sqrt{\text { ste }}$ placed in imperfective unsuffixed template

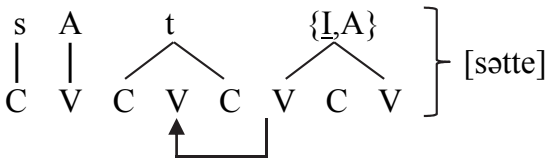

The representation in (9) accounts for the quality of the final vowel rather brutally, i.e., by simply assuming that it is there underlyingly. The question is immediately raised as to what happens in the [a]-suffixed case [satja], where the third radical is realized as [j]. Consider what we expect to find when placing $\sqrt{\text { ste }}$ in the same template as [rakba], as in (10). The final vowel, as we have seen, must be underlyingly long (and harmony applies to the base vowel). The template is also lexically specified for the medial geminate. $\mathrm{V}_{3}$ is governed; for this reason, I submit, the third radical /e/ has no other option but to associate to $\mathrm{C}_{4}$. Since [e] cannot function as a glide, the resulting phonetic realization is the glide version of the head I, namely $[\mathrm{j}]$. Because of the consonantal realization of the root $/ \mathrm{e} /$, the medial V-slot of the geminate is not governed; just like in (8b) above, the geminate is simplified.

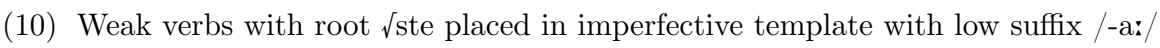

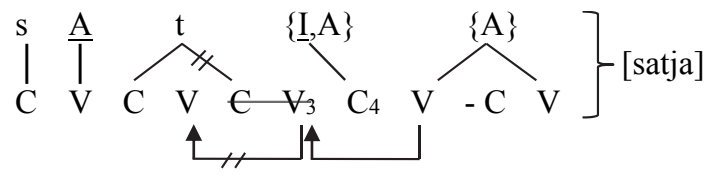


That the vowel /e/ should be realized as a high glide cannot surprise any phonologist familiar with common strategies of hiatus resolution. In Element Theory terms, one may say that because the complex expression $\{\mathrm{I}, \mathrm{A}\}$ is associated with a C-slot, the non-head A cannot be part of the realization, as A does not have a glide equivalent.

More intriguing is the third type of weak stem [sətt-u], because the suffix $[-\mathrm{u}]$ parallels an [-o] in the strong verb [rəkb-o]. Moreover, the third element of the weak root disappears completely. Let us first examine what the result is of placing the weak root in the same template as the strong one. The situation in strong verbs, which was already examined in (8b) above, is presented again in (11b). The parallel situation in weak-final verbs is presented in (11a). Why does (11a) yield [səttu], and not *[sətto], *[sətjo], etc.?

(11) Placing the weak root in the same /o/-suffixed template as the strong root

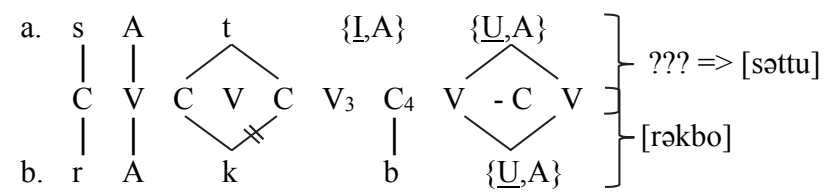

The problematicity of (11a) can be attributed to the adjacency of the two elements with head status - I and $\underline{U}$ - on the Back/Round tier (as per (3) above). None of the conceivable gliding scenarios of this sequence is attested in Tigre: it is an empirical fact that the diphthongs ${ }^{*}[\mathrm{Cjo}]$ and *[Cew] are impossible in this language. I propose instead the rule in (12) which, in prose, says "whenever two vocalic expressions with heads on the back/round tier are concatenated with no intervening consonant, they coalesce into one expression which contains only the head of the second expression".

(12) Rule of Back/Round tier coalescence

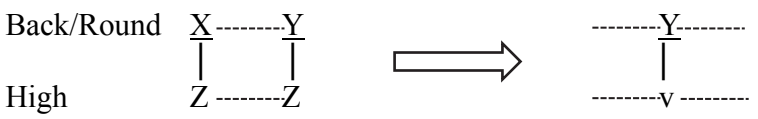

The rule in (12) is admittedly ad-hoc. It also seems unnatural: why would the non-head disappear from both expressions in the output? While I do not have a satisfactory answer for this question, we will see how (12) applies elsewhere in the data, dissipating the present ad-hoc impression. ${ }^{10}$

10 Another question raised by (12) is what motivates the preservation of the second head, rather than the first. Again, I do not have a good answer to this question. The fact 
The result of the application of (12) to the weak-final verb is depicted in (13): The third element of the root coalesces with the suffix $\{\underline{U}, A\}$ to leave $\{\mathrm{U}\}$. The vocalic realization of the coalesced expressions makes it possible for the templatic geminate to surface, unlike in the parallel strong verbs. In strong verbs, the rule does not apply; and the suffix remains [-o]. Note, in addition, that the suffixal vowel delinks from its original position and comes to occupy a stretch that originally belonged to the base. This, I assume, is made possible through the coalescence rule.

(13) Applying back/round tier coalescence to (11a)

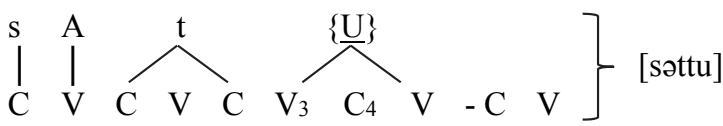

The representation in (13) illustrates another necessary assumption of the present analysis. While affixes come with skeletal support, once rules like coalescence apply, the segmental make-up of the affix may come to occupy the skeletal support of the base. I assume that peripheral, empty CV units as the suffixal CV in (13) are subsequently truncated.

For the sake of completeness, consider the 2FMSG form of the strong verb [ti-rəkbi], and the parallel weak-final verb [ti-sətti]. The present analysis predicts an underlying sequence /ti-sotte-i/ in the latter. The back/round tier coalescence rule is at play in this form, too, although in a less salient manner: the sequence /...e-i/ is predicted to reduce to the head of the suffix, namely to $/ \mathrm{i} /$, yielding the correct form [tisətti]. Again, the gemination of the template may consequently surface in the weak form, unlike in the parallel strong form.

This subsection was devoted to the imperfective paradigm. It was argued that the phoneme /e/ is the third radical of weak-final verbs. Its vocalic nature, however, leads to realizations which do not replicate exactly the patterns of the strong verbs. With the help of a rule of back/round tier coalescence and some standard generalizations about template satisfaction, it was shown that these realizations follow from the assumption about the nature of the third radical. No further statement is required: weak-final verb forms are constructed with the same templatic space and the same vocalization as strong ones.

Yet the rule of back/round tier coalescence is for the time being only circularly motivated by the facts it was devised to explain. It finds addi-

correlates with the strong tendency to delete $\mathrm{V}_{1}$ rather than $\mathrm{V}_{2}$ in hiatus resolution (Casali 1997; see Balogné Bérces 2006 for an account in Strict CV Phonology). 
tional confirmation in the next subsection, where the perfective paradigm is discussed.

\subsection{The perfective}

Consider the weak-final and strong perfective paradigms in (14), keeping in mind the phonological generalizations that we have accumulated. Right away, one notices the alternation between [ə] and [a] in both vowels of the strong verbs - a sure sign that these vowels are /a/ underlyingly. Another salient fact concerning the weak paradigm is the presence of the vowel [e] in all of the cases where the suffix is consonant-initial. Besides this fact, more or less expected given the analysis in the preceding subsection, [e] appears also before the otherwise vowel-initial 3FSG suffix, but completely disappears before the vowel-initial suffixes of the 3MSG, 3MSPL and 3FMPL.

(14) Strong and weak-final perfective paradigms in Tigre

\begin{tabular}{|l|l|l|l|}
\cline { 3 - 4 } \multicolumn{2}{c|}{} & 'find' & 'drink' \\
\hline SG & 1 & rəkəb-ko & səte:-ko \\
\hline \multirow{6}{*}{$2 \mathrm{M}$} & rakab-ka & səte:-ka \\
\cline { 2 - 4 } & $2 \mathrm{~F}$ & rəkəb-ki & səte:-ki \\
\cline { 2 - 4 } & $3 \mathrm{M}$ & rakb-a ${ }^{11}$ & sat-a \\
\cline { 2 - 4 } & 3F & rəkb-ət & sate:-t \\
\cline { 2 - 4 } & \multicolumn{2}{c}{} & \multicolumn{2}{c}{}
\end{tabular}

\begin{tabular}{|l|l|l|l|}
\cline { 2 - 4 } \multicolumn{2}{c|}{} & 'find' & 'drink' \\
\hline PL & 1 & rakab-na & səte-na \\
\hline \multirow{1}{*}{} & $2 \mathrm{M}$ & rəkəb-kum & səte-kum \\
\cline { 2 - 4 } & 2F & rəkəb-kən & səte-kən \\
\cline { 2 - 4 } & 3M & rəkb-əw & sət-əw \\
\cline { 2 - 4 } & 3F & rakb-aja & sat-aja \\
\cline { 2 - 4 } & & \multicolumn{2}{c}{}
\end{tabular}

Before these differences are accounted for, a word must be said about the position of some morpheme boundaries in (14).

\subsubsection{3rd person suffixes}

In the strong paradigm, there are clearly two surface stems: the preconsonantal one [rəkəb] and the pre-vocalic one [rəkb]. I will now propose a single stem /rəkəb/, whose second vowel is "floating": it is not lexically anchored to its position. As a result, its realization depends on grammatical factors, and it may not always surface in the same position.

If one assumes the mobility of the second stem vowel $/ \mathrm{\partial} /$, doubt is shed on several morpheme boundaries in (14), namely the 3FMSG [-ət], 3MPL [-əw], 3FMPL [-aja]. Is their initial vowel part of the suffix, or is it the mobile stem vowel? I submit the latter is true. The reanalyzed part of

11 The final [a] of the 3MSG.PRF, unlike other final [a]'s, alternates with long [e:] upon further suffixation: [rakbe:-ka] 'find.3MSG.PRF-OBJ.2MSG'. 
(14) is presented again in (15). Note that the analysis of the 3MSG remains the same:

(15) Reanalyzed 3rd person forms of the perfective

\begin{tabular}{|l|l|l|l|}
\cline { 3 - 4 } \multicolumn{2}{l|}{} & 'find' & 'drink' \\
\hline SG & $3 \mathrm{M}$ & rakb-a & sat-a \\
\hline \multirow{3}{*}{} & $3 \mathrm{~F}$ & rəkbə-t & sate:-t \\
\cline { 2 - 4 } & &
\end{tabular}

\begin{tabular}{|l|l|l|l|}
\cline { 3 - 4 } \multicolumn{2}{l|}{} & 'find' & 'drink' \\
\hline \multirow{2}{*}{ PL } & $3 \mathrm{M}$ & rəkbə-w & sətə-w \\
\cline { 2 - 4 } & $3 \mathrm{~F}$ & rakba-ja & sata-ja \\
\cline { 2 - 4 }
\end{tabular}

If I am correct, the only V-initial suffix is 3MSG [-a]. The other three seemingly $\mathrm{V}$-initial suffixes are in fact $\mathrm{C}$-initial. Unlike the other C-initial suffixes ([-ko],[-ki] etc.), they are not followed by a vowel. This view carries two economy-based advantages. First, the 3MPL is reduced to a round vocalic element - exactly as in the 2MPL and 3MPL of the imperfective $/-\mathrm{o} /$. Second, the feminine suffix is only $[-\mathrm{t}]$ elsewhere in the language, with the preceding vowel usually determined by context ([gurum-girmit] 'beautiful (M-F)' [buzuh-bizhat] 'many (M-F)'). ${ }^{12}$

Representations of the different forms will appear in the next subsection, in which the strong and weak-final paradigms are contrasted and accounted for, and a third advantage emerges: the proposed analysis makes the correct predictions for weak-final verbs.

\subsubsection{The inflected forms}

If the strong verb has the unique perfective base /rəkəb/, the weak-final stem is predicted to be /sətəe/. There are five surface forms that one must account for if this underlying stem is posited:

(16) Surface vocalizations to account for in the weak perfective
a. Before CV: [səte:-ko]
c. Before $[-w]$ : $[$ sətə-w]
e. Before [-a]: [sat-a]
b. Before C: [səte:-t]
d. Before [-ja]: [sata-ja]

Let us begin with [səte:-ko] (16a). The template of the perfective is consistently $\mathrm{CəCəCV}$ (with a second mobile /ə/, see below). As shown in (17a), the stem material thus has only three CV units at its disposal. The

${ }^{12}$ Further support for the mobility of the second stem vowel can be found in the paradigms of strong verbs with guttural-final roots, such as [farha] 'he was scared'. By analogy to [rəkəb-ko] 'I found', one expects [fərəh-ko] 'I was scared'. But Tigre disallows gutturals in internal coda position (i.e., before governed empty nuclei); instead, one finds an [ə] after the guttural: [fərhə-ko]. This [ə] must belong to the stem: the epenthetic vowel in Tigre is [i]. In this context, note that Meyer (2006) also analyzes the 3FSG perfective suffix of the related Wolane language as /-t/. 
template cannot accommodate both the second vowel of the vocalization and the third radical /e/, which must branch. As a result, the two vowels coalesce and yield a single long [e:], as shown in (17b). ${ }^{13}$

(17) Pre-consonantal perfective stems: [sate:-ko]

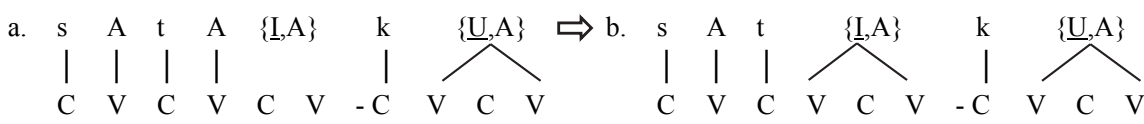

One may assume that the coalescence of $\{\mathrm{A}\}$ and $\{\underline{\mathrm{I}}, \mathrm{A}\}$ is possible because the former is unheaded. At any rate, a diphthong [əj] is not attested in Tigre word-medially.

To explain [səte:t] (16b), let us begin with the parallel strong form [rəkbət]. The suffix /-ko/ in (17) was accompanied by two CV units, to accommodate the consonant and the long vowel. The suffix [-t] is thus represented as accompanied by only one CV unit, as in (18a). As proposed in the previous subsection, in this strong form the stem's /o/ ends up associating to $\mathrm{V}_{3}$ (probably in order to prevent a final cluster, illicit in Tigre). In contrast, in the parallel weak-final form in (18b), no final cluster is predicted, because the third radical does not necessarily have to be associated to the C-slot. Indeed, the same situation is encountered as in (17a) above. Accordingly, the same coalescence scenario applies, resulting in a stem vowel [e:].

(18) The weak perfective forms: the stem before 3FMSG suffix /-t/

a.

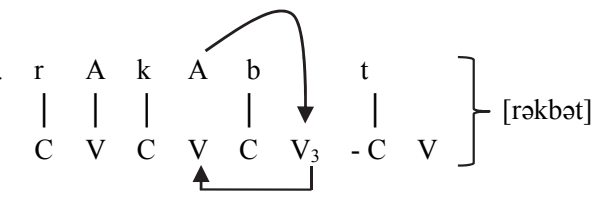

b.

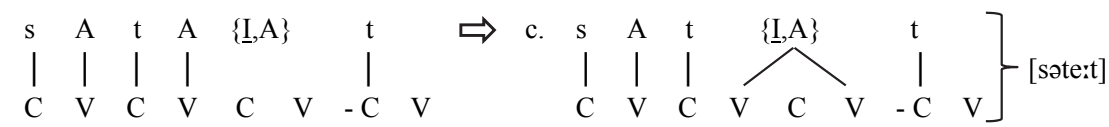

This analysis was made possible by the assumption that the 3FSG was $/ \mathrm{t} /$, rather than /-ət/. If the latter were the case, the weak form would be /sətəeət/. The surface result [səte:t] would be harder to motivate.

Let us proceed to the plural suffix [-w], and begin with the representation of strong [rəkbəw]. In the previous subsection, I assumed that [w]

${ }^{13}$ For reasons of space, I do not represent [rəkəb-ko], the account of which is straightforward. 
is underlyingly identical to the imperfective /-o/. If so, it must be introduced with the same number of CV units, i.e., one. However, unlike the imperfective stem, the perfective stem involves two vowels /ə/ that require realization. As shown in (19a), this can be achieved by mapping the second /a/ to the stem-final position, as in the 3FSG. This mapping creates the problem of hiatus, which can be resolved either through coalescence or through diphthongization. In this case, I propose, the diphthong attested is motivated by the need to realize both the stem vocalization and the affix separately. ${ }^{14}$

The parallel weak-final form [sətəw] (16c) follows naturally from this representation in combination with the back/round tier coalescence rule. The two expressions at the right edge in (19a) coalesce in (19c) into one containing only the head of the second. Because the preceding segment is itself a vowel, the result of the Back/Round coalescence rule is a glide, not a vowel.

(19) The weak perfective forms: the stem before 3MPL suffix /-o/

a.
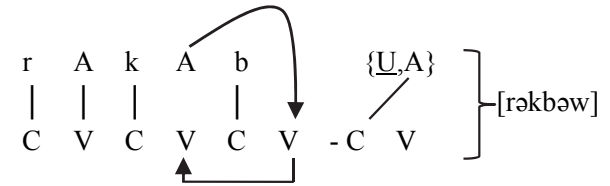

b.

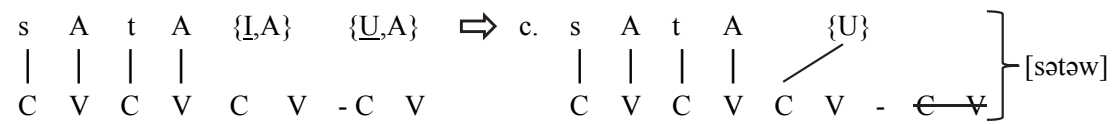

In the analysis of the imperfective, the rule of back/round tier coalescence was simply posited on the basis of the observed data. It lacked independent motivation. I have shown that this rule is at play in the derivation of the different perfective forms, too. Thus, the rule is less ad-hoc than it might have seemed originally.

In fact, the same rule is active in the derivation of the 3FPL [sataja] in (16d), cf. [rakbaja]. Let us begin again with the strong verb. In the previous subsection, I have suggested that the suffix is the glide initial [-ja]. The glide component in this suffix is interesting: the parallel 3FPL suffix in the imperfective and subjunctive paradigms is simply [-a] (and used for the 2FPL, too). However, if the perfective suffix were [-a], too, this would create an identity with the 3MSG [rakba]. Possibly for this reason, a specific

${ }^{14}$ Note that in [sett-u] ((13) above), it is the root material, not the stem vocalization, that is deleted. 
affix [ja] emerged for the perfective 3FPL. One may ask what the underlying representation of this suffix is: as we saw, underlyingly geminated $/ \mathrm{j} /$ is realized as simplex, so there are two candidates /-jja: and /-ja:/. Because the former is predicted to be more stable, and the entire point of the establishment of this suffix is for it not to be reduced to [a], I will assume that the feminine suffix contains an underlying geminate/-jja:/, as represented in (20a). Since the vowel of the suffix, like all final vowels, is long underlyingly, the suffix must be introduced with three CV units. The second / / / of the stem is again associated to its final V-slot, and the underlying / rəkbəjja: / is realized as [rakbaja]. On to the weak-final form in (20b), we encounter once again two expressions headed by elements residing on the Back/Round tier (here it is the same element twice). The rule predicts a process of coalescence leaving only $\{\underline{I}\}$. In $(20 \mathrm{c})$, this remaining element occupies the available templatic stretch of two C-slots to yield the UR/sətəjja:/. The rightmost part of the template is truncated, and the correct realization [sataja] emerges.

(20) The weak perfective forms: the stem before 3FMPL suffix /-jja:/

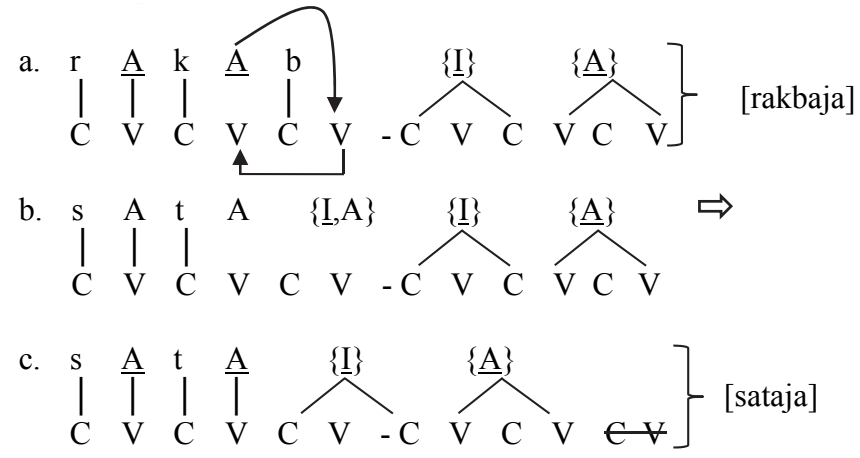

Finally, we come to the 3MSG. In the strong from [rakb-a], one does not find the second stem vowel. This absence is expected if, as shown in (21a), the vowel of the suffix occupies the final V-slot of the base, thereby governing the preceding nucleus. The parallel weak-final form [sata] (16e) is possibly the most intriguing of all weak-final forms, because it seems to have absolutely no trace of the third radical. By analogy to the strong [rakba], one might expect the strong glide realization of $/ \mathrm{e} /{ }^{*}[$ satja]. There is nothing wrong phonologically with this form; indeed, it is the form of the $2 / 3 \mathrm{FPL}$ imperfective discussed and presented in (10) above. Still, the attested form is [sata]. 
The reason is revealed when one examines the expected underlying form of the perfective 3MSG. By analogy to the pre-syncope /rəkəba:/, we expect the initial representation to be /sətəea:/. Unlike in the $2 / 3 \mathrm{FPL}$ imperfective, where the radical /e/ was post-consonantal, here it is in the weak intervocalic position. In (20) above, it was shown that an intervocalic geminate glide is realized as a singleton [j]. In contrast, if the representation of [rakba] in (21a) is correct, then the /e/ of the parallel weak-final form in (21b) cannot be geminated: it simply does not have enough space. As a result, I submit, it disappears from the structure, leaving only a stretch of A's, which amounts to the representation in (21c) ${ }^{15}$

(21) Strong and weak $3 \mathrm{MSG}$ perfect forms ${ }^{16}$

a.

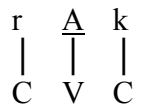

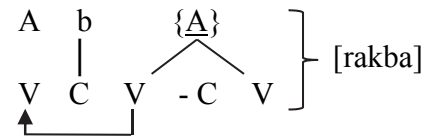

b.

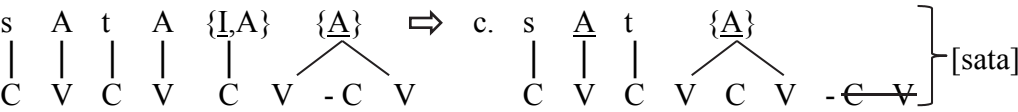

In the preceding subsection, the claim was made that contrary to appearances, the 3rd person suffixes were consonant-initial (except for the 3MSG). This view was argued for on economic grounds, since $[\mathrm{t}]$ and /o/ have the same denotations elsewhere. In this subsection, the same view was shown to make correct predictions regarding the forms of the weak-final paradigm. The last subsection of the analysis is devoted to the subjunctive paradigms.

\subsection{The subjunctive}

The relevant paradigms are presented in (22). There are three different scenarios to account for. First, in the unsuffixed stems, the vowel of the strong stem is [ə], and that of the weak stem [e]. Second, before glidable non-low vocalic elements, the vocalization of both strong and weak stems is [ə], but in the strong stem, the suffix is a vowel [rkəb-o/i], whereas in the

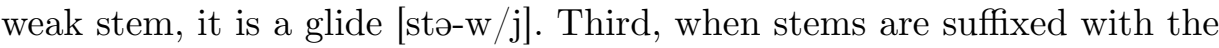

${ }^{15}$ Note that the configuration in (20b) is different from the one in the IMP.2/3FSG [satja] in (10) above. In that configuration, the radical /e/ is preceded by an empty nucleus, whereas in $(20 \mathrm{~b})$ it is preceded by $/ \mathrm{a} /$.

${ }^{16}$ Coalescence must be preferred over government and syncope in $(21 \mathrm{~b}, \mathrm{c})$ due to the stretch of underlying $/ \mathrm{A} / \mathrm{s}$. 
low vowel [-a], the vowel of both stems is a short [a], but a glide [j] appears in the weak stem where the third consonant appears in the strong verb.

(22) Weak and strong subjunctive paradigms

\begin{tabular}{|l|l|l|l|}
\cline { 2 - 4 } \multicolumn{2}{c|}{} & 'find' & 'drink' \\
\hline SG & 1 & í-rkəb & í-ste \\
\hline \multirow{6}{*}{} & $2 \mathrm{M}$ & tí-rkəb & ti-ste \\
\cline { 2 - 4 } & $2 \mathrm{~F}$ & tí-rkəb-i & ti-stə-j \\
\cline { 2 - 4 } & $3 \mathrm{M}$ & li-rkəb & lí-ste \\
\cline { 2 - 4 } & $3 \mathrm{~F}$ & ti-rkəb & ti-ste \\
\cline { 2 - 4 } & &
\end{tabular}

\begin{tabular}{|l|l|l|l|}
\cline { 2 - 4 } \multicolumn{2}{|c|}{} & 'find' & 'drink' \\
\hline PL & 1 & ni-rkəb & ni-ste \\
\hline \multirow{4}{*}{} & $2 \mathrm{M}$ & ti-rkəb-o & tí-stə-w \\
\cline { 2 - 4 } & $2 \mathrm{~F}$ & ti-rkab-a & tí-staj-a \\
\cline { 2 - 4 } & $3 \mathrm{M}$ & li-rkəb-o & li-stə-w \\
\cline { 2 - 4 } & 3F & ti-rkab-a & tí-staj-a \\
\cline { 2 - 4 } & &
\end{tabular}

The strong verb exhibits a stem /rkəb/ throughout: its straightforward paradigm will therefore not be represented here. The weak-final unsuffixed stem is by analogy /stəe/, and its realization as [ste] is expected, the two vowels coalescing into a long /e:/ (cf. (17) above):

(23) Subjunctive unsuffixed stem

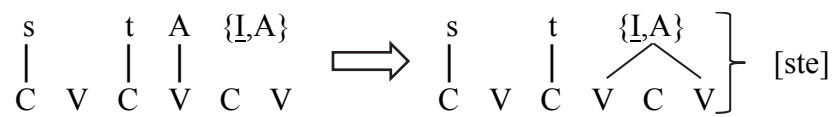

Unlike [rəkbəw] in (19a) above, where a sequence /əo/ gave a dipthong [əw], the sequence /əi/ in (23) yields [ste], not *[stəj]. Recall however that in (19a) the diphthongization was claimed to be the result of a need to distinguish between base and affix; in (23) the / $\mathrm{i} /$ is part of the stem.

Forms carrying a non-low vocalic suffix are correctly predicted by the back/round tier coalescence rule, as shown in (24). The suffixes /-o, -i/ are concatenated to the stem. They involve the elements $U$ and I respectively, which trigger the coalescence rule, resulting in the disappearance of the last radical. Because the stem ends in a vowel, the coalesced expression must be syllabified as a consonant. ${ }^{17}$

(24) Subjunctive stems with glidable suffixes: /stəe-o/ $\Rightarrow$ [stəw], /stəe-o/ $\Rightarrow$ [stəw]

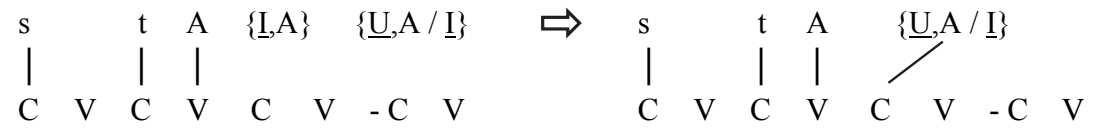

17 (24) is similar to the imperfective 2/3MPL [səttu] ((11) above) and the parallel 2FSG [sətti]. The differences in realizations stem from the absence of a second vowel in the imperfective stem. In addition, the realization of unsuffixed underlying / /e/ as [e] rather than [əj] in (23) was attributed to the fact that the two sounds were part of the stem; in (24), the final vowel is again not part of the stem and must be realized separately. 
The last form to be discussed is the $2 / 3 \mathrm{FPL}$ [staj-a], cf. strong [rkab-a]. I submit the suffix in these forms is accompanied by two CV units (25a). Its vowel, unable to glide, occupies the last two $\mathrm{V}$-slots. As a result, the radical /e/ may occupy the two C-slots between the stem /o/ and the suffixal /a/. Again, when associated with consonantal positions /e/ is realized as [j] if geminated, as it is in (25a). In the strong verb, in contrast, the vowel of the suffix will occupy the last V-slot of the template (25b). ${ }^{18}$

(25) Subjunctive stems with non-glidable suffixes: [staja] (25a), [rkaba] (25b)

a.

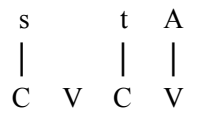

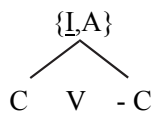<smiles>[Mg][AlH]</smiles>

b.
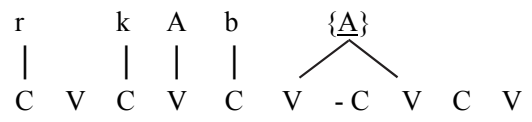

Compare (25) to the perfective 3MSG ((21) above), which also carries a suffix [-a:] but results in the non-realization of the radical, [sata] 'he drank'. In (21), the suffix is accompanied by a single CV, and is thus obliged to "invade" the final V-slot of the stem, imposing syncope. But in (25), no such invasion is necessary. The additional CV in (25) correlates with the complex morphosyntactic structure of a feminine plural, as opposed to the basic 3MSG.

The comprehensive account of both inflectional paradigms is now complete.

\section{Conclusion}

Weak verbs feature in all Semitic languages. Weak-final verbs are by far the most common, appearing in almost every verbal template, alongside strong verbs. Descriptions often attribute their weakness to an unstable element in the root, usually $/ \mathrm{j} /$ or $/ \mathrm{w} /$, but it is very rarely shown how the actual inflected forms are derived from such propositions. In this paper, I examined the full inflectional paradigms of Tigre weak-final and strong verbs (in Type A). I showed that, under the assumption that the weak element is the root-final /e/, all the forms in both paradigms can be derived within the phonology, with no appeal to morphology.

${ }^{18}$ Of course, another possibility is the gemination of the final $/ \mathrm{b} /$. Presumably, this possibility is not attested because unlike in the weak radical of (25a), the last radical of $(25 \mathrm{~b})$ can be realized as a singleton, too. 


\section{References}

Backley, Phillip. 2011. An introduction to Element Theory. Edinburgh: Edinburgh University Press.

Balogné Bérces, Katalin. 2006. What's wrong with vowel-initial syllables? SOAS Working Papers in Linguistics 14. 15-21.

Carvalho, Joaquim Brandão de and Noam Faust. 2017. Vocalic templates and the structure/melody distinction. Paper presented at The Interface Within, Glow 40, Amsterdam.

Casali, Rod. 1997. Vowel elision in hiatus contexts: Which vowel goes? Language 73. 493-533.

Chekayri, Abdellah and Tobias Scheer. 2003. The appearance of glides in Classical Arabic defective verbs. Folia Orientalia 39. 7-33.

Elias, David L. 2014. The Tigre language of Ginda ${ }^{\varsigma}$, Eritrea. Leiden: Brill.

Faust, Noam. 2014. Templatic metathesis in Tigre imperatives. Phonology 31. 209-227.

Faust, Noam. 2015. Eroded prefixes, gemination and guttural effects in Tigre: An account in CVCV phonology. Natural Language and Linguistic Theory 33. 1209-1234.

Faust, Noam. 2017a. Apophony in the inflections of weak and strong verbs in Palestinian Arabic. The Linguistic Review 34. 83-124.

Faust, Noam. 2017b. Get that into your head: Tigre vowel harmonies as templatic. Glossa 2. 95 .

Faust, Noam and Nicola Lampitelli. 2020. The two i's of Qaraqosh Neo-Aramaic. Journal of Semitic Studies 65. 35-60.

Faust, Noam and Shanti Ulfsbjorninn. 2018. Arabic stress in Strict CV, with no moras, no syllables, no feet and no extrametricality. The Linguistic Review 35. 561-600.

Gussmann, Edmund and Jonathan Kaye. 1993. Polish notes from a Dubrovnik café. SOAS Working Papers in Linguistics and Phonetics 3. 427-462.

Kaye, Jonathan D., Jean Lowenstamm and Jean-Roger Vergnaud. 1985. The internal structure of phonological elements: A theory of charm and government. Phonology Yearbook 2. 305-328.

Kaye, Jonathan D., Jean Lowenstamm and Jean-Roger Vergnaud. 1990. Constituent structure and government in phonology. Phonology 7. 193-231.

Leslau, Wolf. 1945. Short grammar of Tigré. New Haven: American Oriental Society.

Lowenstamm, Jean. 1996. CV as the only syllable type. In J. Durand and B. Laks (eds.) Current trends in phonology. Models and methods. Salford: European Studies Research Institute, University of Salford Publications. 419-441.

Lowenstamm, Jean and Jean-François Prunet. 1988. Tigre vowel harmonies. Rapport Annuel du Groupe de Recherche sur la Linguistique Africaniste au CRSH 1987-88. Montréal: Université du Québec à Montréal.

McCarthy, John J. 2005. The length of stem-final vowels in Colloquial Arabic. In M. T. Alhawary and E. Benmamoun (eds.) Perspectives on Arabic linguistics XVII-XVIII. Amsterdam \& Philadelphia: John Benjamins. 1-26.

Meyer, Ronny. 2006. Wolane: Grammar of an East Gurage language (Ethiosemitic) (Grammatical Analyses of African Languages 31). Köln: Köppe. 
Palmer, Frank R. 1956. 'Openness' in Tigre: A problem in prosodic statement. Bulletin of the School of Oriental and African Studies 18. 561-577.

Raz, Shlomo. 1980. The morphology of the Tigre verb (Mansaf dialect). Journal of Semitic Studies 25. 66-84; 205-238.

Raz, Shlomo. 1983. Tigre grammar and texts. Malibu, CA: Undena Publications.

Scheer, Tobias. 2004. A lateral theory of phonology. Vol 1: What is CVCV, and why should it be? Berlin \& New York: Mouton de Gruyter.

Voigt, Rainer. 2004. Der Wegfall der Personalelemente in den Präfixkonjugationen des Semitischen. Studia Aetiopica in honour of Siegbert Uhlig on the occasion of his 65th birthday. Wiesbaden: Harrasowitz.

Voigt, Rainer. 2009. Das Präsens im Tigre. Aethiopica 12. 155-163. 